\section{6 update of the EULAR recommendations for the management of rheumatoid arthritis: a utopia beyond patients in low/middle income countries?}

We read with great interest the recently published recommendations by the European League against Rheumatism (EULAR) on the management of rheumatoid arthritis (RA). ${ }^{1}$ The EULAR recommendations, although primarily targeted towards European countries, are read and followed across the world including low/middle income nations. Consequently, we were disappointed to note that the updated guidelines recommend the use of biological disease-modifying anti-rheumatic drugs (bDMARDs) or targeted synthetic DMARDs (tsDMARDs) immediately following failure of monotherapy with conventional synthetic DMARDs (csDMARDs) in those patients with poor prognostic factors such as seropositivity for rheumatoid factor (RF) or anticitrullinated peptide antibodies (ACPA), highly active disease or early radiographic joint damage (recommendation number 8$).^{1}$ This is in contrast to the 2015 guidelines provided by the American College of Rheumatology (ACR) for the management of RA, ${ }^{2}$ which offer the option of either combining csDMARDs or using bDMARDs or tofacitinib (tsDMARD) following failure of methotrexate monotherapy in RA, irrespective of the presence or absence of such poor prognostic indicators. Early use of bDMARDs in the management of RA poses certain specific problems, as discussed below.

Rheumatoid arthritis is one of the most common rheumatic diseases. ${ }^{3}$ We exemplify India to provide an estimate of the actual burden of RA in a low/middle income country. The population prevalence of RA in India is $0.75 \% .^{4}$ According to the 2011 Census of India, with a population of 1.21 billion, ${ }^{5}$ an estimated 9 million people could be affected with RA. Approximately $30 \%$ patients with RA will respond to methotrexate monotherapy. ${ }^{6}$ A vast majority of patients with RA have an adverse prognostic factor in the form of seropositivity for RF or ACPA. Hence, in a country like India, most of 6.3 million patients with RA would require bDMARDs as per current guidelines. The healthcare costs of providing long-term bDMARDs to such a large number of patients, mostly without medical insurance or social security, are beyond the capacity of individual patients or governments of most low/middle income countries. This is an even bigger problem when one considers that there is a paucity of guidelines on when to taper and stop DMARDs, including bDMARDs in RA, as also mentioned in the current EULAR recommendations (recommendations 11 and 12). ${ }^{1}$

With this background, we strongly suggest that the costeffective strategy of treating RA with a combination of csDMARDs when methotrexate monotherapy fails should not be ignored, despite the presence of poor prognostic factors. The TACIT trial confirmed that use of csDMARDs was non-inferior to the use of anti-tumor necrosis factor (TNF) agents in the management of RA, but associated with substantially lesser costs. ${ }^{7}$ It is pertinent to note that most of the trials on bDMARDs in RA, which established their utility for this indication, did so with a combination of bDMARDs and methotrexate. ${ }^{8}$ This is emphasised in the current EULAR guidelines which recommend the addition of methotrexate or other csDMARD to bDMARD or tsDMARD in phase II of the treatment strategy (recommendation 9). ${ }^{1}$ This brings forth an interesting conundrum, that is, how much of the disease-modifying effect of the bDMARDs was attributable to itself vis-à-vis methotrexate? For example, a closer look at the PREMIER study ${ }^{9}$ shows that outcomes at 2 years in terms of the proportion of patients attaining ACR 20, ACR 50 and ACR 70 responses were numerically better or equal for methotrexate monotherapy when compared with adalimumab monotherapy. Two excellent meta-analyses by Graudal et $a l^{1011}$ reaffirm that the use of bDMARDs is associated with earlier attainment of ACR 50 and ACR 70 responses and numerically lesser radiographic progression of RA in the first 2 years. However, the difference disappears at 2 years of therapy. Moreover, the use of csDMARDs in combination is associated with significantly lesser costs.

Nevertheless, it cannot be denied that the advent of bDMARDs has revolutionised the management of RA in the modern era. However, this must be weighed against the marked immunosuppressive state resulting from the use of bDMARDs, which is a major concern in low/middle income countries wherein infections like tuberculosis are endemic. Use of anti-TNF bDMARDs has been reported to cause infections like leprosy in regions of the world where this disease was not believed to exist like the USA, in a patient who never reported travelling outside this geographical region. ${ }^{12}$ This suggests that the use of bDMARDs should be undertaken with due caution under all circumstances.

To conclude, we suggest that combination of csDMARDs should still be considered a viable alternative to bDMARDs or tsDMARDs in patients with RA failing initial monotherapy with methotrexate under most circumstances. A strategy of using a combination of csDMARDs upfront in patients with poor prognostic factors, as suggested by the previous ACR recommendations, ${ }^{13}$ may be more reasonable in resource-constrained scenarios. Such patients who fail csDMARDs in combination at 3-6 months should be considered for bDMARDs or tsDMARDs. This might help rationalise the economic burden due to bDMARDs or tsDMARDs, while not depriving the appropriate patient of timely treatment with these drugs. The enthusiasm of using bDMARDs upfront should be tempered with pragmatism and caution given lack of definitive evidence of superiority to csDMARDs in combination, significantly higher costs and risk of infections, especially in low/middle income countries.

Durga Prasanna Misra, ${ }^{1}$ Vikas Agarwal, ${ }^{1}$ Aman Sharma, ${ }^{2}$ Anupam Wakhlu, ${ }^{3}$ Vir Singh Negi ${ }^{4}$

${ }^{1}$ Department of Clinical Immunology, Sanjay Gandhi Postgraduate Institute of Medical Sciences (SGPGIMS), Lucknow, India

${ }^{2}$ Cinical Immunology and Rheumatology Services, Department of Internal Medicine, Postgraduate Institute of Medical Education and Research (PGIMER), Chandigarh, India

${ }^{3}$ Department of Rheumatology, King George's Medical University, Lucknow, India

${ }^{4}$ Department of Clinical Immunology, Jawaharlal Institute of Postgraduate Medical

Education and Research (JIPMER), Puducherry, India

Correspondence to Dr Durga Prasanna Misra, Department of Clinical Immunology, C block, 2nd floor, Sanjay Gandhi Postgraduate Institute of Medical Sciences (SGPGIMS), Rae Bareily Road, Lucknow-226014, India; durgapmisra@gmail.com, dpmisra@sgpgi.ac.in

Contributors DPM, VA, VSN - conception and design of the paper. DPM, VA, AS, AW-acquisition of data, analysis and interpretation of data. DPM, VA-drafting the article. AS, AW, VSN-revising it critically for important intellectual content. DPM, VA, AS, AW, VSN-final approval of the version to be submitted.

Competing interests None declared.

Provenance and peer review Not commissioned; internally peer reviewed. 
To cite Misra DP, Agarwal V, Sharma A, et al. Ann Rheum Dis 2017;76:e47.

\section{Received 9 March 2017}

Accepted 11 March 2017

Published Online First 27 March 2017

\section{Linked}

http://dx.doi. org/10.1136/annrheumdis-2017-211455

Ann Rheum Dis 2017;76:e47. doi:10.1136/annrheumdis-2017-211446

REFERENCES

1 Smolen JS, Landewé R, Bijlsma J, et al. EULAR recommendations for the management of rheumatoid arthritis with synthetic and biological disease-modifying antirheumatic drugs: 2016 update. Ann Rheum Dis 2017. doi: 10.1136/ annrheumdis-2016-210715. [Epub ahead of print 6 Mar 2017]

2 Singh JA, Saag KG, Bridges SL, Jr, et al. 2015 American College of Rheumatology Guideline for the Treatment of Rheumatoid Arthritis. Arthritis Rheumatol 2016;68:1-26.

3 Cross $M$, Smith E, Hoy D, et al. The global burden of rheumatoid arthritis: estima from the Global Burden of Disease 2010 study. Ann Rheum Dis 2014;73:1316-22.

4 Misra DP, Agarwal V, Negi VS. Rheumatology in India: a Bird's eye view on organization, epidemiology, training programs and publications. J Korean Med Scites 2016;31:1013-19.

5 http://www.censusindia.gov.in/Census_Data_2001/National_Summary/National_ Summary_DataPage.aspx (accessed 8 Mar 2017).

6 Moreland LW, O'Dell JR, Paulus HE, et al. A randomized comparative effectiveness study of oral triple therapy versus etanercept plus methotrexate in early aggressive rheumatoid arthritis: the treatment of Early Aggressive Rheumatoid Arthritis Trial. Arthritis Rheum 2012;64:2824-35.

7 Scott DL, Ibrahim F, Farewell V, et al. Tumour necrosis factor inhibitors versus combination intensive therapy with conventional disease modifying anti-rheumatic drugs in established rheumatoid arthritis: TACIT non-inferiority randomised controlled trial. BMJ 2015;350:h1046.

8 Parida JR, Misra DP, Wakhlu A, et al. Is non-biological treatment of rheumatoid arthritis as good as biologics? World I Orthop 2015;6:278-83.

9 Breedveld FC, Weisman MH, Kavanaugh AF, et al. The PREMIER study: A multicenter, randomized, double-blind clinical trial of combination therapy with adalimumab plus methotrexate versus methotrexate alone or adalimumab alone in patients with early, aggressive rheumatoid arthritis who had not had previous methotrexate treatment. Arthritis Rheum 2006;54:26-37.

10 Graudal N, Jürgens $\mathrm{G}$. Similar effects of disease-modifying antirheumatic drugs, glucocorticoids, and biologic agents on radiographic progression in rheumatoid arthritis: meta-analysis of 70 randomized placebo-controlled or drug-controlled studies, including 112 comparisons. Arthritis Rheum 2010;62:2852-63.

11 Graudal N, Hubeck-Graudal T, Faurschou M, et al. Combination therapy with and without tumor necrosis factor inhibitors in rheumatoid arthritis: a meta-analysis of randomized trials. Arthritis Care Res (Hoboken) 2015;67:1487-95.

12 Scollard DM, Joyce MP, Gillis TP. Development of leprosy and type 1 leprosy reactions after treatment with infliximab: a report of 2 cases. Clin Infect Dis 2006;43:e19-22.

13 Singh JA, Furst DE, Bharat A, et al. 2012 update of the 2008 American College of Rheumatology recommendations for the use of disease-modifying antirheumatic drugs and biologic agents in the treatment of rheumatoid arthritis. Arthritis Care Res (Hoboken) 2012;64:625-39. 